\title{
Enhancement of Thermal Performance of Heat Pipe Using Hybrid Nanofluid
}

\author{
Kamble D.P. ${ }^{1}$, Gadhave P.S. ${ }^{2}$, M.A.Anwar ${ }^{3}$ \\ ${ }^{12}$ Assistant Professor, Mechanical Engineering Department, DCOER, Pune, India \\ ${ }^{3}$ Assistant Professor, Mechanical Engineering Department, SCSCOE, Pune, India
}

\begin{abstract}
The presents the behaviour of nanofluid to improve the thermal performance of a circular heat pipe. The heat pipe is made of straight copper tube using hybrid nanofluid $\left(\mathrm{Al}_{2} \mathrm{O}_{3}+\right.$ $\mathrm{CuO}$ ) with water base as working fluids. An experimental setup is designed and constructed to study thermal performance of the heat pipe under different operating conditions. Total thermal performance of heat pipe for pure water and water based nanofluid is predicted. This study presents a discussion on the effects of the charged volume ratio of the working fluids. The effect of filling volume ratio, volume fraction of nano particles in the base fluid on the thermal resistance is investigated. Thermal performance of heat pipe increases with increasing $\left(\mathrm{Al}_{2} \mathrm{O}_{3}+\mathrm{CuO}\right)$ -water based nanofluid compared to that of pure water.
\end{abstract}

Keywords - Heat pipe, Hybrid nanofluid, thermal resistance.

\section{INTRODUCTION}

In different processes ranging from conversion, utilization \& recovery of thermal energy in various industrial, commercial $\&$ domestic applications heat exchangers are used. More economical design of heat exchanger which can help to make energy, material \& cost savings related to a heat exchange process by increase in performance of Heat exchanger.

Use of Heat transfer enhancement techniques lead to increase in heat transfer coefficient but at the cost of increase in pressure drop. So, while designing a heat exchanger using any of these techniques, analysis of heat transfer rate \& pressure drop has to be done.

To achieve high heat transfer rate in an existing or new heat exchanger several techniques have been proposed in recent years. This work presents the study of heat transfer enhancement of a circular heat pipe using $\mathrm{Al}_{2} \mathrm{O}_{3}-\mathrm{CuO} /$ water hybrid nanofluid.

\section{METHODS AND REVIEW}

Tsai et al. performed an experiment concerning a cylindrical mesh wick heat pipe. The working fluid was an aqueous solution of various-sized gold nanoparticles. The inner diameter and the length of the test copper tube were $6 \mathrm{~mm}$ and $170 \mathrm{~mm}$, respectively. A 200 mesh screen was distributed on the inner wall. The number of mesh layers was unknown. The experimental results showed that the total heat resistance of the heat pipe reduced $20 \%-37 \%$ due to the addition of nanoparticles. Result shows the total resistance of the heat pipe for nanofluids of various particle sizes.
P. Keblinski et al. presented a cylindrical micro-grooved heat pipe with the inner diameter and the length of $6 \mathrm{~mm}$ and $200 \mathrm{~mm}$ respectively. The width and the depth of the rectangular groove were $211 \mathrm{~lm}$ and $217 \mathrm{~lm}$, respectively. The working fluid consisted of silver nanoparticles with an average particle size of $10 \mathrm{~nm}$ and pure water. They mainly measured the total heat resistance of the heat pipe filled with pure water and nanofluids. The total heat resistance of the heat pipe using nanofluids could decrease by $28 \%-44 \%$ compared with that of the heat pipe using water.

Lin et al. investigated experimentally the thermal performance of a closed loop oscillating heat pipe using nanofluids. They applied water-based silver nanofluids at different volume fractions (100 ppm and $450 \mathrm{ppm})$ and various filling ratios $(20 \%, 40 \%, 60 \%$, and $80 \%)$. The silver nanoparticle had a diameter of $20 \mathrm{~nm}$. Results showed that the thermal performance of the oscillating heat pipe using nanofluids was better than that using water. The best filling ratio was reported to be $60 \%$.

\section{EXPERIMENTAL SETUP}

We used oscillating heat pipe which is made of straight copper tube of total length $600 \mathrm{~mm}$ (evaporator length, $150 \mathrm{~mm}+$ adiabaticlength, $300 \mathrm{~mm},+$ condenser length, $150 \mathrm{~mm}$ ), outer diameter $22 \mathrm{~mm}$ with thickness of $2 \mathrm{~mm}$. Pure water and hybrid nanofluid $\left(\mathrm{Al}_{2} \mathrm{O}_{3}+\mathrm{CuO}\right)$ with water base are used as working fluids

In order to enhance the heat transfer experimental system designed with the following specifications, provision is made to vary the heater input by changing the voltage and to study the effect of volume concentration of hybrid nanofluid on thermal resistance of heat pipe three heat pipes with inner fluid as water, $1 \%$ volume fraction of hybrid nanofluid and $2 \%$ volume fraction of hybrid nanofluid are used.

ISSN: 2231-5381 


\section{International Journal of Engineering Trends and Technology (IJETT) - Volume17 Number 9-Nov2014}

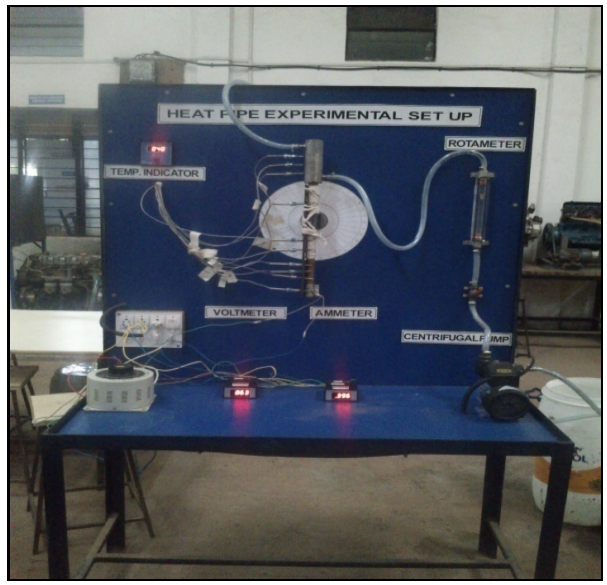

Fig. 1 Experimental setup

This experimental setup consist heat pipe, rotameter, pump, temperature indicator, dimmer stat voltmeter and ammeter. Heat is provided with the help of heater at the evaporator section of heat pipe and heat is rejected in condenser section.

\section{TEST METHODOLOGY}

The following procedure is followed to perform experiment, 1. The heat pipe is charged with $400 \mathrm{ml}$ of working fluid, which approximately corresponds to the amount required to fill the evaporator. The distance between the evaporator and the condenser is normally called as the adiabatic section with a length of $300 \mathrm{~mm}$.

2. The wall temperature distribution of the heat pipe in adiabatic zone is measured using five evenly spaced, at an equal distance from the evaporator.

3. The adiabatic section of the heat pipe is completely insulated with the asbestos material layer. The amount of heat loss from the evaporator and condenser surface is negligible.

4. The electrical power input is applied at the evaporator section using cylindrical electric heater attached to it with proper electrical insulation and the heater is energized with $230 \mathrm{~V}$ AC supply and measured using a voltmeter and ammeter connected in parallel and series connections respectively.

5. The evaporator and condenser have a length of $150 \mathrm{~mm}$. In order to measure the average temperature of the evaporator, two thermocouples are distributed along the length of evaporator.

6. Water jacket has been used at the condenser end to remove the heat from the pipe. The heat pipe has the ability to transfer the heat through the internal structure. As a result, a sudden rise in wall temperature occurs which could damage the heat pipe if the heat is not released at the condenser properly. Therefore, the cooling water is circulated first through the condenser jacket, before the heat is supplied to the evaporator. 7. The condenser section of the heat pipe is cooled using water flow through a jacket with an inner diameter of $25.4 \mathrm{~mm}$ and outer diameter of $30 \mathrm{~mm}$. The water flow rate is measured using a rota meter on the inlet line to the jacket, the flow rate is kept constant at $6.6 \mathrm{lpm}$, to measure the average temperature of the condenser, three equally spaced thermocouples distributed along the length of condenser.

8. The inlet and outlet temperatures of the cooling water are measured using two thermocouples. The experiments are conducted using three identical heat pipes which are manufactured as per mentioned dimensions. One of the heat pipes is filled with distilled water, second one with $1 \%$ aqueous solution of hybrid nano fluid $\left(\mathrm{Al}_{2} \mathrm{O}_{3}-\mathrm{CuO}\right)$, third one with aqueous solution of $2 \%$ hybrid nano fluid.

9. The power input to the heat pipe is gradually raised to the desired power level. The surface temperatures at five different locations along the adiabatic section of heat pipe are measured at regular time intervals until the heat pipe reaches the steady state condition. Simultaneously the evaporator wall temperatures, condenser wall temperatures, water inlet and outlet temperatures in the condenser zone are measured.

10. Once the steady state is reached, the input power is turned off and cooling water is allowed to flow through the condenser to cool the heat pipe and to make it ready for further experimental purpose.

11. Experimental procedure is repeated for different heat inputs $(25,50,75$ and $100 \mathrm{~W})$.

\section{HEAT PIPE DATA ANALYSIS}

The ultimate aim of the variation of heat input and volume concentration of hybrid nanofluid on circular heat pipe is to study its effect on thermal resistance.

The overall thermal resistance of circular heat pipe is calculate by equation-

$$
\text { Fth }=\frac{\mathrm{Te}-\mathrm{Tc}}{\mathrm{q}}
$$

Where, $T_{e}$ and $T_{c}$ are the average wall temperatures of evaporator and condenser section and can be determined by following equations,

$$
\begin{aligned}
& T a=\frac{1}{n} \sum_{\mathrm{i}=0}^{\mathrm{n}} \mathrm{Ti} \\
& T c-\frac{1}{1} \Sigma \mathrm{m}=\mathrm{Ti}
\end{aligned}
$$

Rate of heat transfer at evaporator section is calculated by

$$
Q=V I
$$

Where, $V$ and $I$ are input voltage and current respectively which is measured by digital voltmeter and ammeter.

\section{EXPERIMENTAL RESULTS AND DISCUSSIONS}

Temperature distributation along the length of horizontal heat pipe using working fluid as water, $1 \%$ vol.fraction \& $2 \%$ volume fraction nanofluid. 


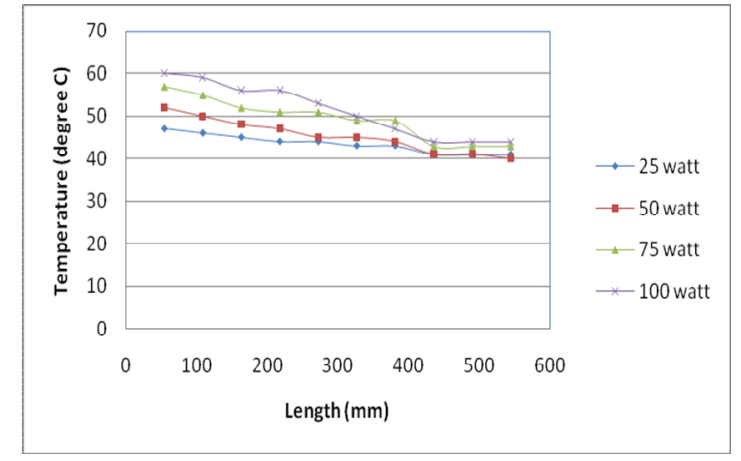

Fig. 2 Temperature distribution along length of heat pipe using water as working fluid

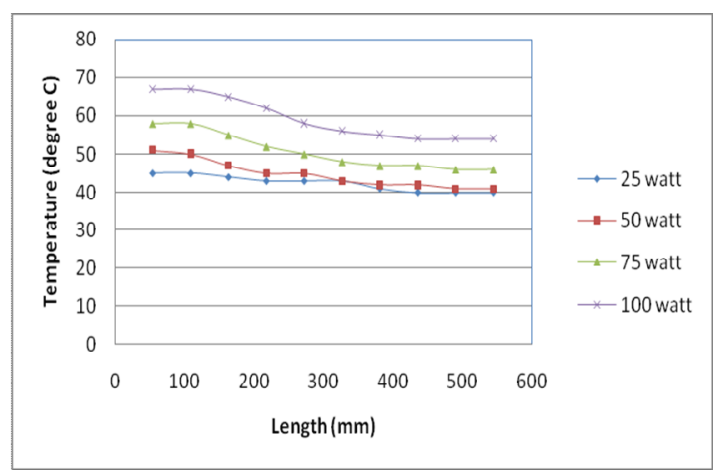

Fig. 3 Temperature distribution along length of heat pipe using $1 \%$ volume fraction of nanofluid as working fluid

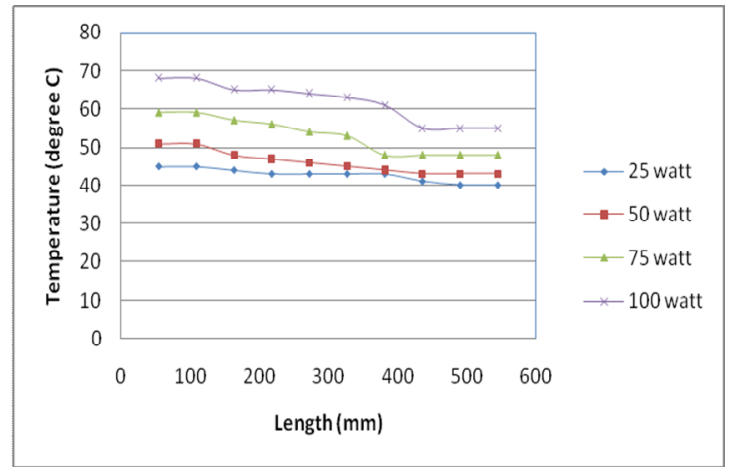

Fig. 4 Temperature distribution along length of heat pipe using $2 \%$ volume fraction of nanofluid as working fluid

Fig. 2 to fig. 4 represents the distribution of wall temperature against length of heat pipe under the different power input and different working fluid of heat pipe i.e. water, $1 \%$ volume fraction of $\mathrm{Al} 2 \mathrm{O} 3-\mathrm{CuO} / \mathrm{H} 2 \mathrm{O}$ hybrid nanofluid, $2 \%$ volume fraction of $\mathrm{Al} 2 \mathrm{O} 3-\mathrm{CuO} / \mathrm{H} 2 \mathrm{O}$ hybrid nanofluid. As seen in fig. 2 by increase in input power, wall temperature also increases. For horizontal heat pipe and 100W power input the temperature difference between evaporator and condenser section is observed as $15.5^{\circ} \mathrm{C}, 13^{\circ} \mathrm{C}$, and $12{ }^{\circ} \mathrm{C}$ when heat pipe charge with water, $1 \%$ and $2 \%$ volume of hybrid nanofluid respectively.

Thermal resistance of heat pipes with working fluid as water, $1 \%$ and $2 \%$ volume fraction of nanofluid are,

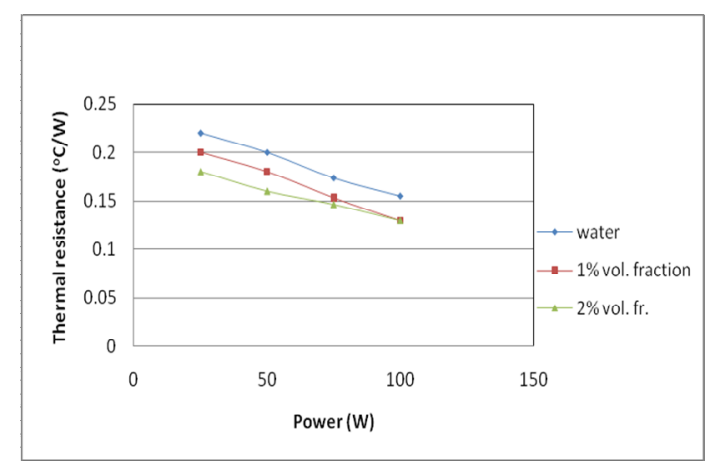

Fig. 5 Variation of thermal resistance with power inputs to heat pipe

Fig. 5 represent thermal resistance vs. power input for heat pipes charged with working fluid as water, $1 \%$ volume fraction of $\mathrm{Al}_{2} \mathrm{O}_{3}-\mathrm{CuO} / \mathrm{H}_{2} \mathrm{O}$ hybrid nanofluid, $2 \%$ volume fraction of $\mathrm{Al}_{2} \mathrm{O}_{3}-\mathrm{CuO} / \mathrm{H}_{2} \mathrm{O}$ hybrid nanofluid.

It is clear that thermal resistance of heat pipes decreases with increasing volume concentration of hybrid nanofluid and increasing heat input. For 100 watt power input the thermal resistance of heat pipe found experimentally is $0.155^{\circ} \mathrm{C} / \mathrm{W}$ with water as working fluid of heat pipe. For the same above mention input thermal resistance of heat pipe charged with $1 \%$ and $2 \%$ hybrid nanofluid found experimentally are 0.13 and $0.13{ }^{\circ} \mathrm{C} / \mathrm{W}$ respectively. Thus percentage decreased in thermal resistance observed is $15.38 \%$.

Variation of Thermal resistance $\left({ }^{0} \mathrm{C} / \mathrm{W}\right)$ with volume fraction of nanofluid $(\%)$ at different power input to heat pipe are as,

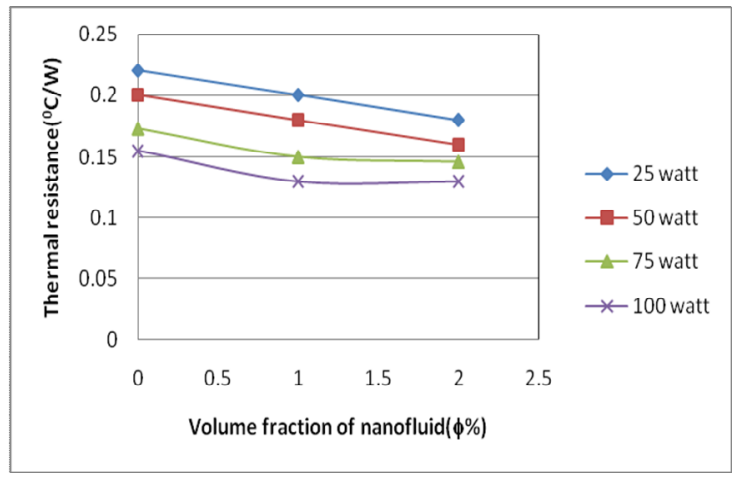

Fig. 6 Variation of Thermal resistance $\left({ }^{0} \mathrm{C} / \mathrm{W}\right)$ with volume fraction of nanofluid $(\%)$

Fig. 6 shows the influence of the hybride nano particle volume fraction on the thermal resistance of heat pipe.The thermal resistance of the hybride nanofluid heat pipe monotonically decreases with increase in the volume fraction. The increase of volume fraction cause the increase of both the thermal conductivity and viscocity of the hybrid nonfluid The thermal conductivity become conciderably larger compare to viscocity of the bybrid nonfluid as the volume fraction increases. This lead to improvement of the evaporation heat 


\section{International Journal of Engineering Trends and Technology (IJETT) - Volume17 Number 9-Nov2014}

transper in liquid film and the thermal resistance of the bybrid nonfuid heat pipe is reduse with increasing volume friction.

\section{CONCLUSION}

This anslysis discusses the thermal enhancement of circular heat pipe performance using $\mathrm{Al}_{2} \mathrm{O}_{3}-\mathrm{CuO} /$ Water hybrid nanofluid as working fluid.For that purpose the effect of different concentration of hybrid nanofluid, inclination angle, heat input on thermal resistance of circular heat pipe is studied. From the experimentation the following conclusions can be drawn

Thermal resistance of circular heat pipe decreases with increase in volume concentration of hybrid nanofluid, increase in heat input and increase in inclination angle compared with distilled water as working fluid.

With increase in the volume concentration of hybrid nanofluid the thermal resistance of circular heat pipe for $2 \%$ volume concentration of hybrid nanofluid as working fluid reduces by an amount of $32.00 \%$ compared with distilled water as working fluid.

With increase in the inclination angle of circular heat pipe the thermal resistance reduces. for $2 \%$ volume concentration and variation in inclination angle from $0^{\circ}$ to $90^{\circ}$ for hybrid nanofluid as working fluid thermal resistance reduces by an amount of $34.62 \%$ compared with distilled water as working fluid.

With increase in the heat input of hybrid nanofluid the thermal resistance of circular heat pipe reduces. For variation in heat input from $25 \mathrm{~W}$ to $100 \mathrm{~W}$ and for $2 \%$ volume concentration of hybrid nanofluid as working fluid it reduces by an amount of $39.28 \%$ compared with distilled water as working fluid.

From the above experimentation it is concluded that the circular heat pipe using hybrid nanofluid as working fluid can give the promising results compared with water as working fluid.

\section{FUTURE SCOPE}

In recent paper single nanofluid used as working media in different type of heat pipes. In futuer aspect two nanofluids or more nanofluids will be using as working media in different heat pipes and determine the effect of thermal performance of two or more nanofluds i.e.hybrid nanofluds used on different concentration and different inclination angle of heat pipes.

The direction of the future research on the application of nanofluids in heat pipes is mainly.

To find the optimal types of nanofluids to achieve the best thermal performance find out nano particle size and nano particle concentration. Also, it is also a hot spot for future research

To and the impacts of various operating parameters, such as the operating temperature, the heat flux and the ambient temperature on the heat transfer enhancement of nanofluids in heat pipes.

To find the effect on overall heat transfer coefficient and Heat transfer rate with variation in base Fluid of Hybrid Nanofluid in connection with Heat Pipe.

To Find the thermel Performance of heat pipe for different angle of Inclination.

To Find the thermel Resistance of heat pipe for different angle of Inclination, particle size, various concentration of nanofluid.

\section{REFERENCES}

[1] S.U.S. Choi, J.A. Eastman, enhancing thermal conductivity of fluid with nanoparticles, in: D.A. Siginer, H.P. Wang (Eds.), Developments and Applications of Non-Newtonian Flows, ASME, New York, USA, 1995, pp. 99-105.

[2] P. Keblinski, S.R. Phillpot, S.U.S. Choi, J.A. Eastman, Mechanisms of heat flow in suspensions of nano-sized particles (Nanofluids), Int. J. Heat Mass Transfer 45 (2002) 855-863.

[3] M. Wegmuller, J. P. von der Weid, P. Oberson, and N. Gisin, "High resolution fiber distributed measurements with coherent OFDR," in Proc. ECOC'O0, 2000, paper 11.3.4, p. 109.

[4] M. Wegmuller, J. P. von der Weid, P. Oberson, and N. Gisin, "High resolution fiber distributed measurements with coherent OFDR," in Proc. ECOC'00, 2000, paper 11.3.4, p. 109

[5] P. Keblinski, J.A. Eastman, D.G. Cahill, Nanofluids for thermal transport, Mater. 8(2005)36-44.FLEXChip Signal Processor (MC68175/D), Motorola, 1996.

[6] X.Q. Wang, A.S. Mujumdar, Heat transfer characteristics of nanofluids: a review, Int. J. Thermal Sci. 46 (2007) 1-19.

[7] A. Karnik, "Performance of TCP congestion control with rate feedback: TCP/ABR and rate adaptive TCP/IP," M. Eng. thesis, Indian Institute of Science, Bangalore, India, Jan. 1999.

[8] J. Padhye, V. Firoiu, and D. Towsley, "A stochastic model of TCP Reno congestion avoidance and control," Univ. of Massachusetts, Amherst, MA, CMPSCI Tech. Rep. 99-02, 1999. 